\title{
Proteomic analysis of differentially expressed proteins in hepatitis B virus-related hepatocellular carcinoma tissues Ning Li ${ }^{1}$, Yunzhu Long ${ }^{2}$, Xuegong Fan*3, Hongbo Liu ${ }^{3}$, Cui Li ${ }^{4}$, Lizhang Chen ${ }^{5}$ and Zhiming Wang ${ }^{6}$
} \begin{abstract}
Diseases, the First Hospital of Zhuzhou, Zhuzhou 412000, PR China, ${ }^{3}$ Department of Infectious Diseases, Xiangya Hospital, Central South University, Changsha 410008, PR China

Email: Ning Li - nxli@hotmail.com; Yunzhu Long - longyzh73@126.com; Xuegong Fan* -xgfan57@126.com; Hongbo Liu - Illpop@sina.com.cn; Cui Li - licuipwb@yahoo.com.cn; Lizhang Chen - chenliz@mail.csu.edu.cn; Zhiming Wang -Wangzhm64@126.com

* Corresponding author
\end{abstract}

Address: ${ }^{1}$ Department of Blood transfusion, Xiangya Hospital, Central South University, Changsha 410008, PR China, ${ }^{2}$ Department of Infectious University, Changsha 410008, PR China, ${ }^{4}$ Key Laboratory of Cancer Proteomics of Chinese Ministry of Health, Changsha 410008, PR China, ${ }^{5}$ School of Public Health, Central South University, Changsha 410078, PR China and ${ }^{6}$ Department of Surgery, Xiangya Hospital, Central South

Published: 28 August 2009

Journal of Experimental \& Clinical Cancer Research 2009, 28:122 doi:10.1186/1756-9966-28-122

This article is available from: http://www.jeccr.com/content/28/I/122

(C) $2009 \mathrm{Li}$ et al; licensee BioMed Central Ltd.

This is an Open Access article distributed under the terms of the Creative Commons Attribution License (http://creativecommons.org/licenses/by/2.0), which permits unrestricted use, distribution, and reproduction in any medium, provided the original work is properly cited.
Received: 23 May 2009

Accepted: 28 August 2009

\begin{abstract}
Background: Hepatocellular carcinoma ( $\mathrm{HCC}$ ), a major cause of cancer death in China, is preceded by chronic hepatitis and liver cirrhosis (LC). Although hepatitis B virus (HBV) has been regarded as a clear etiology of human hepatocarcinogenesis, the mechanism is still needs to be further clarified. In this study, we used a proteomic approach to identify the differential expression protein profiles between $\mathrm{HCC}$ and the adjacent non-tumorous liver tissues.
\end{abstract}

Methods: Eighteen cases of HBV-related HCC including 12 cases of LC-developed HCC and 6 cases of chronic hepatitis B (CHB)-developed HCC were analyzed by two-dimensional electrophoresis (2-DE) combined with matrix-assisted laser desorption/ionization time of flight mass spectrometry (MALDI-TOF-MS), and the results were compared to those of paired adjacent non-tumorous liver tissues.

Results: A total of 17 differentially expressed proteins with diverse biological functions were identified. Among these, 10 proteins were up-regulated, whereas the other 7 proteins were downregulated in cancerous tissues. Two proteins, c-Jun $\mathrm{N}$-terminal kinase 2 and ADP/ATP carrier protein were found to be up-regulated only in CHB-developed HCC tissues. Insulin-like growth factor binding protein 2 and Rho-GTPase-activating protein 4 were down-regulated in LCdeveloped and CHB-developed HCC tissues, respectively. Although II out of these 17 proteins have been already described by previous studies, or are already known to be involved in hepatocarcinogenesis, this study revealed 6 new proteins differentially expressed in HBV-related HCC.

Conclusion: These findings elucidate that there are common features between CHB-developed HCC and LC-developed HCC. The identified proteins are valuable for studying the hepatocarcinogenesis, and may be potential diagnostic markers or therapeutic targets for HBVrelated $\mathrm{HCC}$. 


\section{Introduction}

Hepatitis B virus (HBV)-related hepatocellular carcinoma (HCC) is one of the most common malignancy in the world, especially in China $[1,2]$. HCC is usually preceded by chronic hepatitis and liver cirrhosis (LC). The common clinical evolution from chronic hepatitis, LC and ultimately to HCC suggests that the carcinogenesis of HCC is a complex process involving multiple events and steps. Some molecular pathogenesis studies have been undertaken successfully on the gene (DNA) and transcription (mRNA) levels, however the carcinogenic mechanism of HBV-related HCC still remains poorly understood.

Development of high throughput proteomics approach provides a new tool to study the pathogenesis of HCC [3]. Proteomics has been used to characterize the molecular events occurring in various disease processes. The twodimensional electrophoresis (2-DE) followed by mass spectrometry (MS) analysis is the principal step of proteomics to identify the comparative expression profiles at the protein level that may be associated with specific diseases. Such approaches are expected to establish the molecular definition of the nontumor and tumor states and contribute to the discovery of diagnostic markers and therapeutic targets.

There are already some previous proteomic studies for HCC, yet the proteomic analysis of HBV-related hepatocarcinogenesis still needs to be further clarified. The aim of the present study was to carry out a differential profiling of proteins from HBV-related HCC samples and their corresponding adjacent non-tumorous liver tissues including chronic hepatitis and LC tissue using matrixassisted laser desorption/ionization time of flight mass spectrometry (MALDI-TOF-MS). The results presented here are expected to obtain some clues to further study the carcinogenic mechanisms, or identify some possible molecular markers for HBV-related HCC.

\section{Materials and methods \\ Materials and chemicals}

2-DE equipment, Imagescanner, ImageMaster 2D Elite 4.01 analysis software, semi-dry system (TE70 series SemiDry Transfer Unit), protein assay kit and supply materials (Immobiline DryStrips pH 3-10L, $24 \mathrm{~cm}, 13 \mathrm{~cm}$, pharmalytes) were purchased from Amersham Biosciences. Other chemicals were mainly obtained from Amersham Biosciences. Trypsin was obtained from Sigma. All chemicals were of analytical reagent grade. Applied Biosystem Voyager -DETM STR Biospectrometry ${ }^{\mathrm{TM}}$ workstation System 4307 MALDI-TOF-MS was purchased from Applied Biosystems.

\section{Liver tissue samples}

Human liver tissue samples used in this study were selected from 18 patients who had undergone partial hepatectomy for HBV-related HCC at the Xiangya Hospital during the period 20032005 [see Table 1]. All HCC patients were diagnosed based on clinical data, including image evidence, histopathological examination [4], and there was no evidence of co-infection with other hepatotropic viruses. Further possible causes of liver damage, such as alcohol, drugs or autoimmune diseases were also excluded. According to Edmonson pathologic grading,

Table I: The main chracteristics of 18 HCC cases

\begin{tabular}{|c|c|c|c|c|c|c|c|c|}
\hline \multirow[t]{2}{*}{ Case } & \multirow[t]{2}{*}{ Gender } & \multirow[t]{2}{*}{ Age (years) } & \multicolumn{4}{|c|}{ HBV infection } & \multirow{2}{*}{$\begin{array}{l}\mathrm{HCV} \\
\text { RNA }\end{array}$} & \multirow[t]{2}{*}{ Histopathologic diagnosis of adjacent non-tumorous tissues } \\
\hline & & & $\mathrm{HbsAg}$ & $\mathrm{HbeAg}$ & anti-HBc & DNA & & \\
\hline I & $M$ & 48 & + & + & + & + & - & liver cirrhosis \\
\hline 2 & M & 46 & + & + & + & + & - & liver cirrhosis \\
\hline 3 & $\mathrm{~F}$ & 72 & + & + & + & + & - & liver cirrhosis \\
\hline 4 & $M$ & 28 & + & + & + & + & - & liver cirrhosis \\
\hline 5 & $M$ & 55 & + & + & + & + & - & chronic hepatitis \\
\hline 6 & $\mathrm{~F}$ & 26 & + & + & & + & - & chronic hepatitis \\
\hline 7 & $M$ & 58 & + & + & + & + & - & liver cirrhosis \\
\hline 8 & $M$ & 25 & + & + & + & + & - & liver cirrhosis \\
\hline 9 & $M$ & 41 & + & & + & + & - & liver cirrhosis \\
\hline 10 & $M$ & 36 & + & + & + & + & - & chronic hepatitis \\
\hline 11 & $M$ & 48 & + & + & + & + & - & liver cirrhosis \\
\hline 12 & $\mathrm{~F}$ & 62 & + & + & + & + & - & liver cirrhosis \\
\hline 13 & $M$ & 39 & + & + & & + & - & chronic hepatitis \\
\hline 14 & $M$ & 44 & + & + & + & + & - & liver cirrhosis \\
\hline 15 & $M$ & 50 & + & + & + & + & - & liver cirrhosis \\
\hline 16 & $M$ & 38 & + & + & + & + & - & chronic hepatitis \\
\hline 17 & $\mathrm{~F}$ & 41 & + & + & + & + & - & chronic hepatitis \\
\hline 18 & $M$ & 65 & + & & + & + & - & liver cirrhosis \\
\hline
\end{tabular}


the 18 cases are all grade I. Compared to the tumorous liver tissue, 18 nontumorous liver specimens (taken at a distance of at least $2 \mathrm{~cm}$ from the tumor) including 12 cirrhotic tissue (LC) samples and 6 chronic hepatitis $B$ (CHB) tissue samples were also obtained from the same individuals respectively [5]. Both $\mathrm{LC}$ tissues and $\mathrm{CHB}$ tissues were diagnosed by pathological confirmation. The study was approved by the hospital ethnic committee, and all patients in the study were consentient before tissue donation.

The preparation of tissue protein samples was described previously by Li. et al.[6]. Briefly, representative fragments of tumorous and non-tumorous liver tissue were immediately used to extract the total proteins, or were snap-frozen in liquid nitrogen and stored at $-80^{\circ} \mathrm{C}$ until used for liver protein preparation. The specimens were then carefully sampled, fixed in $10 \%$ formalin, embedded in paraffin and routinely processed for diagnosis purposes. A total of 30 80 mg tissues were grinded into powder in liquid nitrogen, dissolved in $400 \mu \mathrm{l}$ lysis buffer consisting of 7 $\mathrm{mol} / \mathrm{L}$ urea, $2 \mathrm{~mol} / \mathrm{L}$ thiourea, $2 \% \mathrm{NP}-40,1 \%$ Triton X100, $100 \mathrm{mmol} / \mathrm{L}$ DTT, $5 \mathrm{mmol} / \mathrm{L}$ PMSF, 4\% CHAPS, 0.5 $\mathrm{mmol} / \mathrm{L}$ EDTA, $40 \mathrm{mmol} / \mathrm{L}$ Tris, $2 \%$ pharmalyte, $1 \mathrm{mg} / \mathrm{ml}$ DNase I, and $0.25 \mathrm{mg} / \mathrm{ml}$ RNase $\mathrm{A}$, then vortexed, incubated at room temperature for $2 \mathrm{hr}$. The mixture was centrifuged $\left(15000 \mathrm{r} / \mathrm{min}, 30 \mathrm{~min}, 4^{\circ} \mathrm{C}\right)$. The supernatant was the total protein solution. The concentration of the total proteins was assayed with the protein assay kit (Amersham Biosciences) by comparison of the absorbance of the diluted mixtures to a standard curve of bovine serum albumin in the range of $0-50 \mu \mathrm{g} / \mathrm{L}$.

\section{2-DE and image analysis}

2-DE was performed to separate proteins as described in our previous papers [6-8]. The first dimension isoelectric focusing (IEF) electrophoresis was performed using IPG gel strip (pH 3-10 NL, $24 \mathrm{~cm}$ ) on IPGphor (Amersham Biosciences). Briefly, $400 \mu \mathrm{g}$ of protein samples was diluted to $450 \mu \mathrm{L}$ with a rehydration solution $[7 \mathrm{~mol} / \mathrm{L}$ urea, $2 \mathrm{~mol} / \mathrm{L}$ thiourea, $0.2 \%$ DTT and $0.5 \%(\mathrm{v} / \mathrm{v}) \mathrm{pH} 3-$ 10 IPG buffer], and applied to IPG strips (pH 3-10L, 24 $\mathrm{cm}$ ) by $14 \mathrm{~h}$ ehydration at $30 \mathrm{~V}$. The proteins were focused successively for $1 \mathrm{~h}$ at $500 \mathrm{~V}, 1 \mathrm{~h}$ at $1,000 \mathrm{~V}$, and $8.5 \mathrm{~h}$ at $8,000 \mathrm{~V}$ to give a total of $68 \mathrm{kVh}$ on an IPGphor. Focused IPG strips were equilibrated for $15 \mathrm{~min}$ in a solution [6 $\mathrm{mol} / \mathrm{L}$ urea, $2 \%$ SDS, 30\% glycerol, $50 \mathrm{mmol} / \mathrm{L}$ Tris-HCl (pH 8.8), and 1\% DTT], and then for an additional 15 min in the same solution except that DTT was replaced by $2.5 \%$ iodoacetamide. After equilibration, SDS-PAGE was done on Ettan DALT II system (Amersham Biosciences). After SDS-PAGE, gels were stained with silver nitrate according to the protocol of Plusone sliver staining kit (Amersham Biosciences). Each experiment was performed in triplicate.
2-DE maps were obtained by scanning the gels using the Imagescanner. Analysis of the gels was accomplished using the PDQuest analysis software including background subtraction, spots detection, volume normalization and the establishment of a reference gel. Intensity of each protein was quantified by calculation of spot volume after normalization of the image using the total spot volume normalization method multiplied by the total area of all the spots. The calculation of the theoretical molecular weight and $\mathrm{pI}$ values of the identified protein spots is based on algorithms included in the ImageMaster 2D Elite 4.01 analysis software package. Statistical analysis was carried out with SPSS for Windows 10.0 and Excel.

\section{MALDI-TOF-MS}

Differential protein spots were excised from preparative gels using biopsy punches and transferred to a $1.5 \mathrm{ml}$ siliconized Eppendorf tube. Proteins in-gel was digested as previously described [6]. The gel-spots were destained in the destaining solution consisted of $100 \mathrm{mmol} / \mathrm{L} \mathrm{Na}_{2} \mathrm{~S}_{2} \mathrm{O}_{3}$ and $30 \mathrm{mmol} / \mathrm{L} \mathrm{K}_{3} \mathrm{Fe}(\mathrm{CN})_{6}(1: 1)$. The proteins-contained gel-spots were reduced in the reduction buffer consisted of $100 \mathrm{mmol} / \mathrm{L} \mathrm{NH}_{4} \mathrm{HCO}_{3}, 10 \mathrm{mmol} / \mathrm{L}$ DTT for $1 \mathrm{~h}$ at $57^{\circ} \mathrm{C}$, and alkylated in the alkylation buffer consisted of 100 $\mathrm{mmol} / \mathrm{L} \mathrm{NH}_{4} \mathrm{HCO}_{3}$ and $55 \mathrm{mmol} / \mathrm{L}$ iodocetamide in the dark for $30 \mathrm{~min}$ at room temperature. The gel pieces were dried in a vacuum centrifuge. The dried gel-pieces were incubated in the digestion solution consisted of $40 \mathrm{mmol} /$ $\mathrm{L} \mathrm{NH}_{4} \mathrm{HCO}_{3}, 9 \% \mathrm{ACN}$ and $20 \mu \mathrm{g} / \mathrm{mL}$ trypsin(Sigma, St. Louis, USA) for $16 \mathrm{~h}$ at $37^{\circ} \mathrm{C}$. The tryptic peptide mixture was extracted and purified with Millipore ZIPTIP ${ }^{\mathrm{Tm}} \mathrm{C} 18$ column. The purified tryptic peptide mixture was mixed with $\alpha$-cyano-4-hydroxycinnamic acid (CCA) matrix solution, and vortexed lightly. A volume $(1 \mu \mathrm{l})$ of the mixture containing CCA matrix was loaded on a stainless steel plate, and dried in the air. The samples were analyzed with Applied Biosystems Voyager System 4307 MALDITOF Mass Spectrometer (ABI). The parameters were set up as following: positive ion-reflector mode, accelerating voltage $20 \mathrm{kV}$, grid voltage $64.5 \%$, mirror voltage ratio $1.12, \mathrm{~N}_{2}$ laser wavelength $337 \mathrm{~nm}$, pulse width $3 \mathrm{~ns}$, the number of laser shots 50 , acquisition mass range $1000-$ $3000 \mathrm{Da}$, and delay $100 \mathrm{nsec}$, and vacuum degree $4 \times 10^{-}$ ${ }^{7}$ Torr. A trypsin-fragment peak was served as internal standard for mass calibration. A list of the corrected mass peaks was the peptide mass fingerprinting (PMF).

\section{Database analysis}

Proteins were identified with peptide mass fingerprinting data by searching software PeptIdent http:// www.expasy.org/ and Mascot http://www.matrix science.com. Mascot Distiller was used to detect peaks by attempting to fit an ideal isotopic distribution to the experimental data. The searching parameters were set up as following[6,7]: the mass tolerance was \pm 0.5 Dalton; 
the number of missed cleavage sites was allowed up to 1; the cysteine residue was modified as carbamidomethylcys; variable modifications was oxidation $(\mathrm{M})$; the minimum number of matched-peptides was 5; species was selected as homo sapiens(Human); the peptide ion was $[\mathrm{M}+\mathrm{H}]^{+}$; Mass values was monoisotopic; the searching range was within the experimental $\mathrm{pI}$ value $\pm 0.5 \mathrm{pH}$ unit and experimental $\mathrm{Mr} \pm 20 \%$.

\section{Results}

\section{2-DE maps for human liver tissue proteome}

In order to validate the reproducibility, 2-DEs for 18 cases of HBV-related HCC including 12 cases of LC-developed HCC and 6 cases of CHB-developed HCC were repeated for three times. The image analysis showed that these 2DE maps were reproducible. Using this technique, Over 1,000 protein spots were clearly separated on the gels, ranging from 1100-1400 massed between $\mathrm{pH} 3-10$ in three different tissues. A total of 100 well-resolved and matched spots among three tumor-gels were chosen randomly to calculate the deviation of the spot position. The spot positional deviation was $2.47 . \pm 0.25 \mathrm{~mm}$ in the IEF direction, and $2.86 \pm 0.25 \mathrm{~mm}$ in SDS-PAGE direction. For 12 cases of HCC developed from LC, a total of $1281 \pm$ 51 spots were detected in tumorous tissues with an average matching rate of $94.38 \%$, while a total of $1188 \pm 41$ spots were detected in LC tissues, with an average matching rate of $94.95 \%$. For 6 cases of HCC developed from $\mathrm{CHB}$, a total of $1245 \pm 37$ spots were detected in tumor tissues with an average matching rate of $94.69 \%$, while a total of $1235 \pm 31$ spots were detected in hepatitis tissues with an average matching rate of $95.55 \%$. The wellresolved and reproducible 2-DE patterns of HBV-related HCC tissues and non-tumorous liver tissues adjacent to tumors were attained, which are displayed in Figure 1 and Figure 2.

In this study, the 2-DE protein patterns of 12 pairs of tumor/cirrhosis samples and 6 pairs of tumor/hepatitis samples were quantified and mutually matched. In order to preselect protein variations, the protein patterns of tumor and nontumor tissues were set into two classes, and quantities of all detected spots in both classes were compared by the Student's t-test in ImageMaster 2-DE gel analysis software $[6,8]$. The 2-DE profiles were very similar among 18 tumor tissues samples. To construct a 2-DE map, it is important to have a representative sample. Hence, an average electrophoretic map of human HBVrelated HCC tissues was constructed by the comparison of the 2-DE maps from 18 tumor tissues with the ImageMaster 2-DE gel analysis software. The average electrophoresis map included 2076 protein-spots. Similarly, two average electrophoresis maps of 12 cirrhotic tissues and 6 hepatitis tissues were also established with 1987 protein-spots and 1899 protein-spots, respectively. These average elec- trophoresis maps were used to perform the differential expression analysis. The Differential protein spots were defined as spots in 2-DE gels whose expression up-regulated significantly (at least three-fold discrepancy) in more than $50 \%$ certain tissue compared with control tissue. We compared the 2-DE protein patterns of the average gels of tumorous and cirrhotic tissue, 35 differential protein-spots were detected, among which 19 proteins were up-regulated in tumorous tissues, and 16 were upregulated in cirrhotic tissues significantly. As shown in Figure 1, the spots numbers in part A stood for the proteins which were only expressed or over-expressed in tumorous tissues, and the spots numbers in part B stood for the proteins which were only expressed in cirrhotic tissues or down-regulated in tumorous tissues. We also compared the differential protein expression of paired tumorous and chronic hepatitis B liver tissues from 6 patients with HCC. We found that there were 38 differential spots between cancerous tissues and chronic hepatitis tissues, of which 21 differential protein spots were up-regulated in cancerous tissues, while 17 differential protein spots were up-regulated in chronic hepatitis tissues. As shown in Figure 2, the spots numbers in part A stood for the proteins which were only expressed or over-expressed in tumorous tissues, and the spots numbers in part B stood for the proteins which were only expressed in chronic hepatitis tissues or down-regulated in tumorous tissues.

\section{Identification of differentially expressed proteins in HCC developed from $L C$}

The differential protein-spots were excised from the silver stained gels, and digested in-gel with trypsin. The peptide mass fingerprinting (PMF) maps were obtained by MALDI-TOF-MS, and calibrated with Trypsin autodegraded peak $(\mathrm{m} / \mathrm{z}=1993.9772 \mathrm{Da})$. A selected PMF of protein spot 6 was display in Figure 3. The PMF data were used to search the SWISS-PROT, TrEMBL and NCBI databases with PeptIdent or Mascot software. The resulting protein was determined by comprehensively considering the corresponding experimental $\mathrm{pI}, \mathrm{Mr}$, the number of matched-peptides, and the sequence coverage. Among the 35 protein spots, PMF maps of 23 proteins were obtained by MALDI-TOF-MS, and 14 differential proteins were identified. Of the 14 identified proteins, the expressional levels of 8 proteins named Cytoplasmic dynein heavy chain, Nucleolar phosphoprotein B23, Gankyrin, Cytoskeletal 8, Alpha-1-fetoprotein, Lamin B1, Insulinstimulated protein kinase 1 and Cell division cycle protein 27 homolog (CDC27Hs) were up-regulated in cancerous tissues [see Additional file 1], whereas the expressional levels of 6 proteins named Cyclin-dependent kinase inhibitor p12, Cyclin-dependent kinase inhibitor 1, Antioxidant protein 2, Protein disulfide isomerase A2, C-1-tetrahydrofolate synthase and Insulin-like growth fac- 


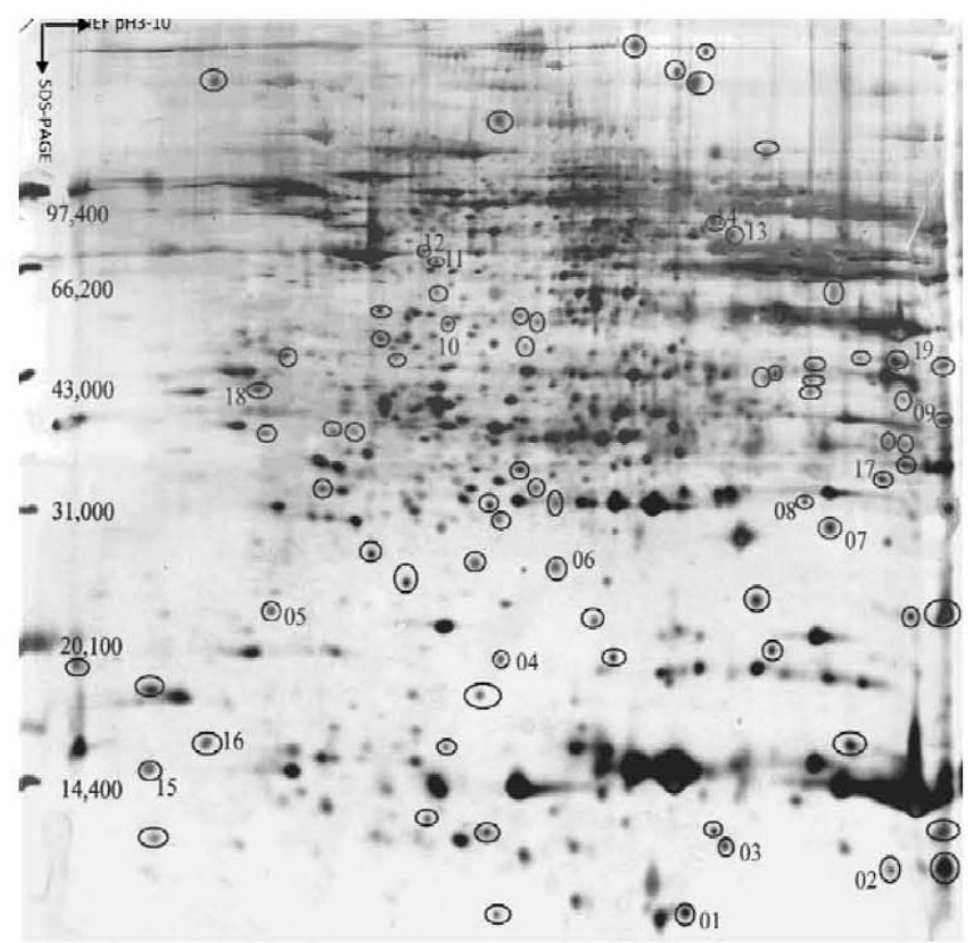

A

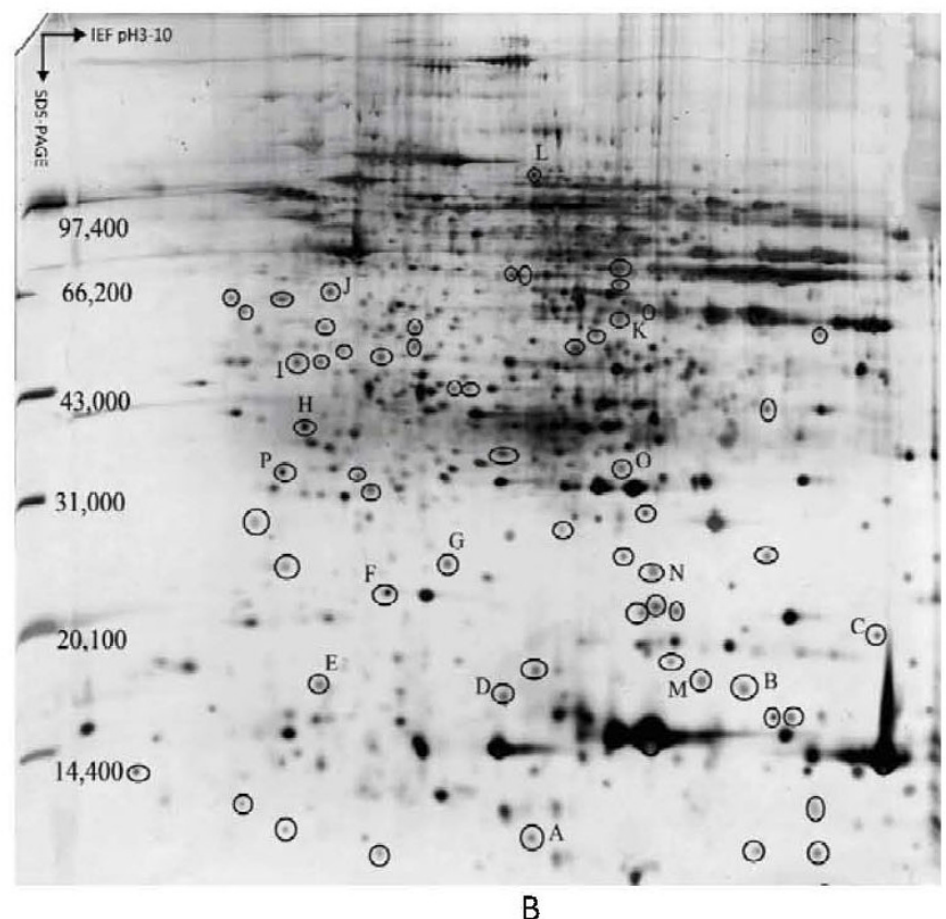

Figure I

Representative silver-stained 2-DE proteins maps obtained from (A) HCC tumorous tissue and (B) adjacent paired liver cirrhosis tissue. The circled protein spots with Arabic numbers in $(A)$ were up-regulated in tumorous tissues. The circled protein spots with English letters in (B) were up-regulated in cirrhotic tissues. 


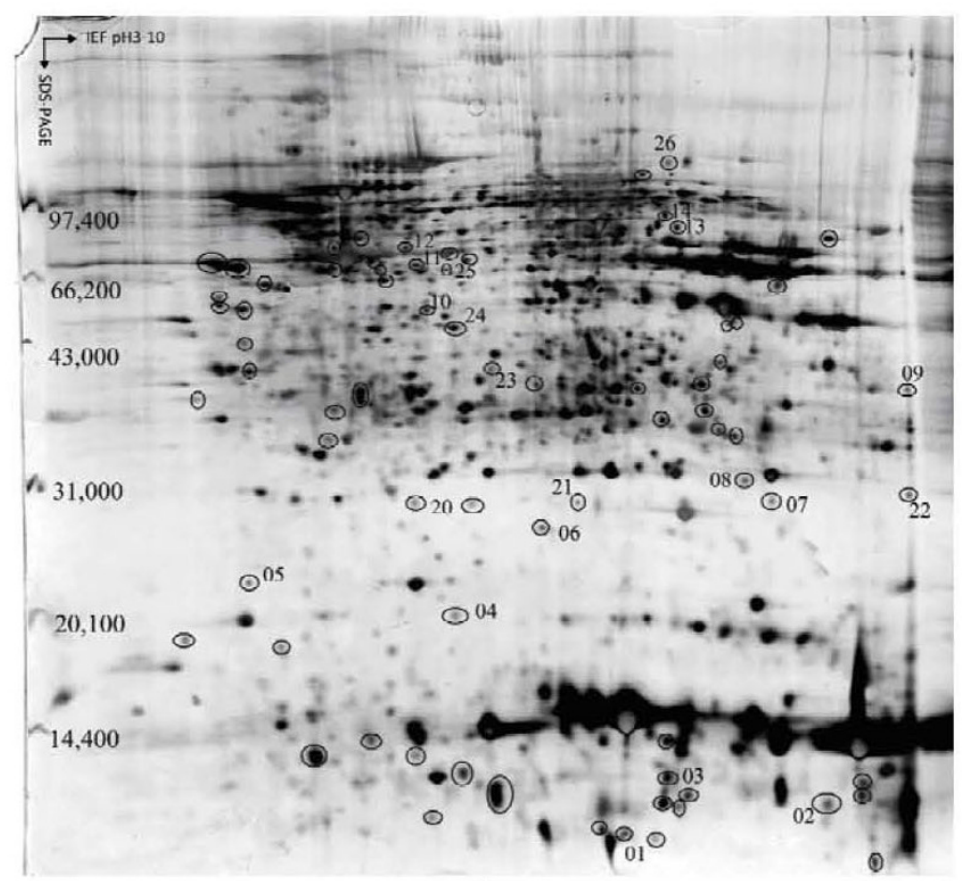

A

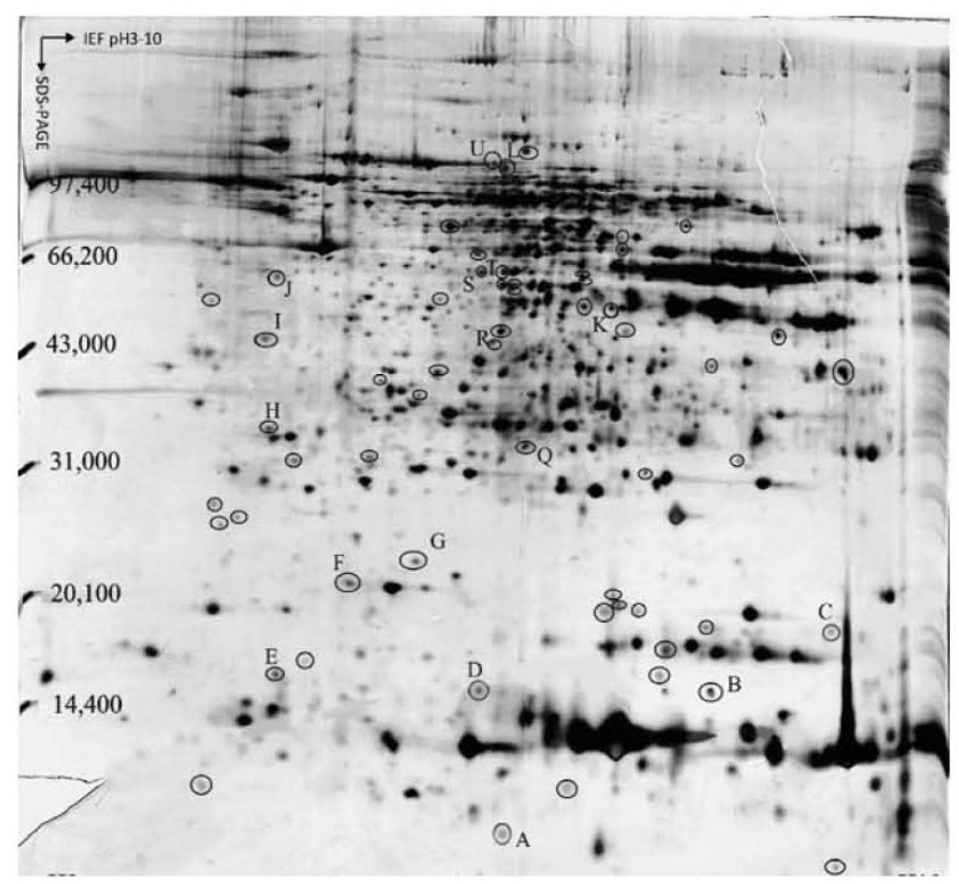

B

\section{Figure 2}

Representative silver-stained 2-DE proteins maps obtained from (A) HCC tumorous tissue and (B) adjacent paired chronic hepatitis tissue. The circled protein spots with Arabic numbers in $(A)$ were up-regulated in tumorous tissues. The circled protein spots with English letters in (B) were up-regulated in chronic hepatitis tissues. 


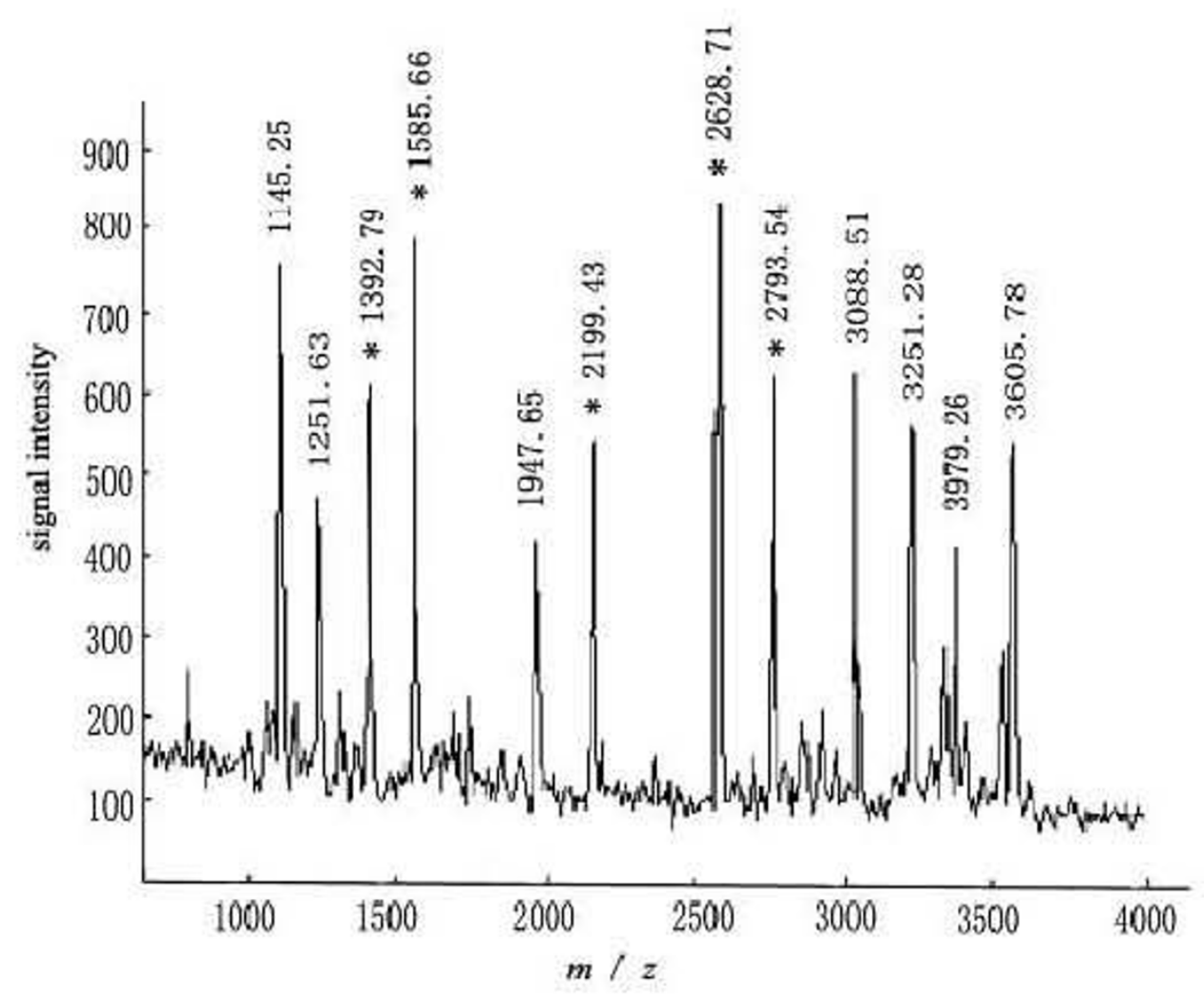

A

1 MEGCVSNLMV CNLAYSGKLE ELKESILADK SLATRTDQDS RTALHWACSA

51 HTEIVEFLL QLGVPVNDKD DAGWSPLHIA ASAGRDEIVK ALLGKGAQVN

101 NGCTPL HYAASKNRHE IAVMLLEGGA NPDAKDHYEA TAMHRAAAKG

151 KMIHILLY YKASTNIQDT EGNTPLHLAC DEERVEEAKL LVSQGASIYI

201 ENKEEKTPLQ VAKGGLGLIL KRMVEG

B

Figure 3

MALDI-TOF-MS analysis of differential protein spot 6. (A) The MALDI-TOF-MS mass spectrum of spot 6, identified as the Gankyrin according to the matched peaks is shown. (B) Protein sequence of Gankyrin is shown, and matched peptides are indicated in bold font and underlined.

tor binding protein 2 were up-regulated in cirrhotic tissues [see Additional file 1].

\section{Identification of differentially expressed proteins in HCC} developed from $\mathrm{CHB}$

Thirty eight differential spots between cancerous tissues and chronic hepatitis tissues had been observed. Using
MALDI-TOF-MS, 24 PMF were successfully obtained, and 16 proteins were identified. Among the 16 identified proteins, 10 proteins were found to be up-regulated in HCC developed from $\mathrm{CHB}$. The up-regulated 10 proteins included 8 above described proteins over-expressed in HCC developed from LC and other two proteins named cJun N-terminal kinase 2 and ADP/ATP carrier protein [see 
Additional file 1]. Six proteins out of 16 identified proteins including 5 above-mentioned proteins which were up-regulated in cirrhotic tissues (Cyclin-dependent kinase inhibitor p12, Cyclin-dependent kinase inhibitor 1, Antioxidant protein 2, Protein disulfide isomerase A2, C1-tetrahydrofolate synthase) and Rho-GTPase-activating protein 4 were up-regulated in chronic hepatitis tissues [see Additional file 1].

\section{Discussion}

HCC is one of the most fatal cancers worldwide, and it is responsible for approximately one million deaths each year. Though the HBV infection is regarded as the most clearly established risk factors, the mechanism is complex and the distinct molecular pathway or molecules involved this phenomenon still remains poorly understood. The possible carcinogenic mechanism of HBV-related HCC is related to the long term-inflammatory changes caused by HBV infection. Chronic hepatitis and cirrhosis are two phases of hepatic necrotizing inflammation caused by HBV infection. Each year, approximate 2\% 3\% patients with LC will develop HCC, and $0.2 \%$ patients with $\mathrm{CHB}$ will develop HCC $[9,10]$. Few studies have been reported concerning the difference between LC-developed HCC and CHB-developed HCC.

MALDI-TOF-MS is a new technique identifying proteins. Since it can rapidly provide a protein expression profile from a variety of biological and clinical samples, many tumorous tissues proteomic studies have been carried out by using this system [11-13]. In this study, the comparative proteomic study was performed between the HCC tissues and the adjacent no-tumorous tissues including $\mathrm{CHB}$ and LC tissues. Seventeen differential protein-spots were identified by MALDI-TOF-MS-based PMF analysis. Eight out of 17 proteins were found to be up-regulated in tumorous tissues of HCC developed from CHB as well as developed from LC. These included Cytoplasmic dynein heavy chain, Nucleolar phosphoprotein B23, Gankyrin, Cytoskeletal 8, Alpha-1-fetoprotein, Lamin B1, Insulinstimulated protein kinase 1 and Protein CDC27HS. Meanwhile, five out of 17 proteins, named Cyclindependent kinase inhibitor p12, Cyclin-dependent kinase inhibitor 1, Antioxidant protein 2, Protein disulfide isomerase A2, C1-tetrahydrofolate synthase were down-regulated both in LC-developed HCC and CHB-developed HCC. However, two identified proteins, c-Jun N-terminal kinase 2 and ADP/ATP carrier protein were found to be up-regulated only in CHB-developed HCC tumorous tissues. The expressions of insulin-like growth factor binding protein 2 and Rho-GTPase-activating protein 4 were upregulated in LC liver tissues and $\mathrm{CHB}$ liver tissues, respectively. Classification of all proteins [see Additional file 1] showed that HCC is such a complicated disease involving multiple-aspects and genes in the differentially expressed proteome at the level of whole-cell extract. Although a few special proteins differentially expressed in CHB-developed HCC or LC-developed HCC, most of identified proteins expressed in both CHB-developed HCC and LCdeveloped HCC, which indicates that there are common features between CHB-developed HCC and LC-developed HCC.

Among the 17 proteins identified in this study, 11 proteins have been already described by previous studies, or are already known to be involved in hepatocarcinogenesis. These proteins are involved in cell growth, proliferation, differentiation, metabolism, cell cycle regulation, cytoskeleton and signal transduction. Importantly, 6 novel proteins including 3 up-regulated proteins (CDC27Hs, ADP/ATP carrier protein, Insulin-stimulated protein kinase 1) and 3 down-regulated proteins (RhoGTPase-activating protein 4, Antioxidant protein 2, C1tetrahydrofolate synthase), were identified in our study. Although these proteins were obtained on a limited number of patients, it should be pointed out that our analysis correctly identified the vast majority of the proteins previously known to be regulated in HCC. It is thus reasonable to assume that the newly identified proteins may be involved in the development of hepatocarcinogenesis or are potential markers of HCC. As a cell cycle regulator, $\mathrm{CDC} 27 \mathrm{Hs}$ colocalizes to the centrosome at all stages of the mammalian cell cycle, and to the mitotic spindle. Injection of affinity-purified anti-CDC27Hs antibodies into logarithmically growing HeLa cells caused a highly reproducible cell cycle arrest in metaphase with apparently normal spindle structure [14]. Some studies indicated that CDC27Hs may be involved in the cancer cell growth $[15,16]$. The role of CDC27Hs in hepatocarcinogenesis needs further study. ADP/ATP carrier protein (AAC) was found to be up-regulated in a larger series of HCC tissues in this study, but down-regulated in notumorous tissues especially in chronic hepatitis B tissues. $\mathrm{AAC}$ is an integral protein present in the inner mitochondrial membrane, which performs the exchange of cytoplasmic and intramitochondrial ADP and ATP. Schulze et al considered the dysfunction of ACC can be induced by some viral infection such as coxsackie B3 virus and leads to an imbalance in myocardial energy metabolism, which is responsible for the impairment of cardiac function $[17,18]$. Recently, the over expression of AAC has already been observed in breast cancer cell [19], and AAC was regarded as a potential biomarker for therapy and prognosis in breast cancer.

The 3 novel down-regulated proteins in this study are mainly involved in metabolism, oxidative stress and proliferation. Rho-GTPase-activating protein 4 (ARHGAP4) is a member of the Rho GTPase activating protein (RhoGAP) family. The RhoGAP family proteins play an 
important role in regulating cell migration, cell morphology and cytoskeletal or ganization [20]. The RhoGAP transcripts were found to be truncated or lowly expressed in some breast carcinoma cell lines, indicating that loss of RhoGAP or its altered activity may suppresse the growth of breast tumor cells [21]. Deleted in liver cancer-1 gene (DLC-1) which is isolated from human hepatocellular carcinoma and encodes a Rho GTPase-activating protein, is frequently inactivated or down-regulated in liver and prostate carcinoma cells [22]. As a tumor suppressor gene, DLC1 significantly inhibits cell proliferation, reduced the motility and invasiveness of hepatocellular carcinoma cells [23]. Our results in this study showed a low expression of ARHGAP4 at the protein level in $83 \%$ of 6 human HCC tested [see Additional file 1]. However, no data have been given to demonstrate the role of ARHGAP4 in hepatocarcinogenesis till now, and the relationship between ARHGAP4 and DLC1 need to be further evaluated. Antioxidant protein 2(AOP2), a unique member of the thiolspecific antioxidant family of proteins, has been shown to remove $\mathrm{H}_{2} \mathrm{O}_{2}$ and protect proteins and DNA from oxidative stress $[24,25]$. Oxidative damage usually leads to decrease ATP level and consequently play an important role in carcinogenesis and metastasis of HCC [26,27]. Increased expression of the stress proteins such as HSP, heat shock cognate (HSC), glucose-regulated protein (GRP) and glycolytic enzymes was found in HCC using 2DE-based proteomics [28]. Ezzikouri et al further defined that hepatitis $\mathrm{B}$ and $\mathrm{C}$ viruses may induce chronic inflammation and oxidative stress, which could predispose a cell to mutagenesis and proliferation [29]. Decreased expression of AOP2 has been previously reported in human prostate cancer [30] and colon cancer cells [31]. In this study, AOP2 was firstly found to be down-regulated in HCC tissues, indicating that HCC cells are in a state of elevated stress and stimulated metabolism. C(1)-tetrahydrofolate (THF) synthase, the eukaryotic trifunctional enzyme, interconvert folic acid derivatives between various oxidation states and is critical for normal cellular function, growth, and differentiation [32]. Howard et al found that the expression patterns of $\mathrm{C}(1)$-THF synthase was involved in liver regeneration [33]. The function and acting mechanisms of this protein await further study.

In conclusion, using 2-DE combined with MS and a stringent statistical analysis, we have been able to identify the differentially proteomic analysis of human HBV-related HCC developed from CHB or LC. Several identified proteins may be potential tumor markers or promising new candidate actors for liver carcinogenesis. Functional studies on selected targets are underway to confirm this hypothesis.

\section{Conflict of interest statement}

The authors declare that they have no competing interests.

\section{Authors' contributions}

NL carried out the 2-DE, participated in MALDI-TOF-MS and drafted the manuscript. YL participated in MALDITOF-MS and performed the database analysis. XF is the corresponding author, conceived of the study and designed the study. HL participated in the preparation of tissue protein. CL mainly participated in the database analysis. LC participated in the design of the study and coordination. ZW participated in the collection of liver tissue samples. All authors read and approved the final manuscript.

\section{Additional material}

\section{Additional file 1}

Identified proteins in HCC tissues using MALDI-TOF-MS. The data provided 17 identified proteins in HCC tissues including 10 up-regulated proteins and 7 down-regulated proteins.

Click here for file

[http://www.biomedcentral.com/content/supplementary/1756-

9966-28-122-S1.doc]

\section{Acknowledgements}

This work was supported by the Key Science Research Fund from Hunan Provincial Health Department (No: Z02-05).

\section{References}

I. Park NH, Song IH, Chung YH: Chronic hepatitis B in hepatocarcinogenesis. Postgrad Med J 2006, 82(970):507-5I5.

2. Xie H, Song J, Du R, Liu K, Wang J, Tang H, Bai F, Liang J, Lin T, Liu J, Fan D: Prognostic significance of osteopontin in hepatitis $B$ virus-related hepatocellular carcinoma. Dig Liver Dis 2007, 39(2): 167-172.

3. Feng JT, Shang S, Beretta L: Proteomics for the early detection and treatment of hepatocellular carcinoma. Oncogene 2006, 25(27):3810-3817.

4. Bruix J, Sherman M, Llovet JM, Beaugrand M, Lencioni R, Burroughs AK, Christensen E, Pagliaro L, Colombo M, Rodés J, EASL Panel of Experts on HCC: Clinical management of hepatocellular carcinoma. Conclusions of the Barcelona-2000 EASL conference. European Association for the Study of the Liver. J Hepatol 200I, 35(3):42I-430.

5. Blanc JF, Lalanne C, Plomion C, Schmitter JM, Bathany K, Gion JM, Bioulac-Sage P, Balabaud C, Bonneu M, Rosenbaum J: Proteomic analysis of differentially expressed proteins in hepatocellular carcinoma developed in patients with chronic viral hepatitis C. Proteomics 2005, 5( I 4):3778-3789.

6. Li C, Xiao Z, Chen Z, Zhang X, Li J, Wu X, Li X, Yi H, Li M, Zhu G, Liang S: Proteome analysis of human lung squamous carcinoma. Proteomics 2006, 6(2):547-558.

7. Li M, Xiao ZQ, Chen ZC, Li JL, Li C, Zhang PF, Li MY: Proteomic analysis of the aging-related proteins in human normal colon epithelial tissue. J Biochem Mol Biol 2007, 40(I):72-8I.

8. Cheng AL, Huang WG, Chen ZC, Peng F, Zhang PF, Li MY, Li F, Li JL, $\mathrm{Li} C, Y_{i} \mathrm{H}, Y_{i} \mathrm{~B}, \mathrm{Xiao}_{\mathrm{ZQ}} \mathrm{Q}$ : Identification of novel nasopharyngeal carcinoma biomarkers by laser capture microdissection and proteomic analysis. Clin Cancer Res 2008, I 4(2):435-445.

9. Bergsland EK: Molecular mechanisms underlying the development of hepatocellular carcinoma. Semin Oncol 200I, 28(5):52|-53I.

10. Lok AS, Heathcote EJ, Hoofnagle JH: Management of hepatitis B: 2000 - summary of a workshop. Gastroenterology 200I, I 20(7): 1828-1853. 
II. Huang YJ, Xuan C, Zhang BB, Liao M, Deng KF, He M, Zhao JM: SELDI-TOF MS profiling of serum for detection of nasopharyngeal carcinoma. J Exp Clin Cancer Res 2009, 28:85.

12. Lee NP, Chen L, Lin MC, Tsang FH, Yeung C, Poon RT, Peng J, Leng $X$, Beretta L, Sun S, Day PJ, Luk JM: Proteomic expression signature distinguishes cancerous and nonmalignant tissues in hepatocellular carcinoma. J Proteome Res 2009, 8(3): I293-303.

13. Zinkin NT, Grall F, Bhaskar K, Otu HH, Spentzos D, Kalmowitz B, Wells M, Guerrero M, Asara JM, Libermann TA, Afdhal NH: Serum proteomics and biomarkers in hepatocellular carcinoma and chronic liver disease. Clin Cancer Res 2008, 14(7):470-477.

14. Tugendreich S, Tomkiel J, Earnshaw W, Hieter P: CDC27Hs colocalizes with CDCI6Hs to the centrosome and mitotic spindle and is essential for the metaphase to anaphase transition. Cell I995, 8I(2):26I-268.

15. Fan CW, Chan CC, Chao CC, Fan HA, Sheu DL, Chan EC: Expression patterns of cell cycle and apoptosis-related genes in a multidrug-resistant human colon carcinoma cell line. Scand J Gastroenterol 2004, 39(5):464-469.

16. Whyte L, Huang YY, Torres K, Mehta RG: Molecular mechanisms of resveratrol action in lung cancer cells using dual protein and microarray analyses. Cancer Res 2007, 67(24): I 2007-I 2017

17. Kato M, Yamashina S, Takeda N Mochizuki S, Morishita T, Nagano M Molecular biological and quantitative abnormalities of ADP/ ATP carrier protein in cardiomyopathic hamsters. Eur Heart J 1995, I 6(Suppl O):78-80.

18. Schulze K, Schultheiss HP: The role of the ADPIATP carrier in the pathogenesis of viral heart disease. Eur Heart J 1995 1 6(Suppl O):64-67.

19. Leirdal M, Shadidy M, Røsok $\varnothing$, Sioud M: Identification of genes differentially expressed in breast cancer cell line SKBR3: potential identification of new prognostic biomarkers. Int J Mol Med 2004, 14(2):217-222.

20. Vogt DL, Gray CD, Young WS 3rd, Orellana SA, Malouf AT: ARHGAP4 is a novel RhoGAP that mediates inhibition of cell motility and axon outgrowth. Mol Cell Neurosci 2007, 36(3):332-342.

21. Nagaraja GM, Kandpal RP: Chromosome I3qI/2 encoded Rho GTPase activating protein suppresses growth of breast carcinoma cells, and yeast two-hybrid screen shows its interaction with several proteins. Biochem Biophys Res Commun 2004, 313(3):654-665.

22. Ullmannova V, Popescu NC: Inhibition of cell proliferation, induction of apoptosis, reactivation of DLCI, and modulation of other gene expression by dietary flavone in breast cancer cell lines. Cancer Detect Prev 2007, 3 I (2): I I0- I I8.

23. Wong CM, Yam JW, Ching YP, Yau TO, Leung TH, Jin DY, Ng IO: Rho GTPase-activating protein deleted in liver cancer suppresses cell proliferation and invasion in hepatocellular carcinoma. Cancer Res 2005, 65(19):886I-8868.

24. Fatma N, Singh DP, Shinohara T, Chylack LT Jr: Transcriptional Regulation of the Antioxidant Protein 2Gene, a Thiol-specific Antioxidant, by Lens Epithelium-derived Growth Factor to Protect Cells from Oxidative Stress. J Biol Chem 200I, 276(52):48899-48907.

25. Kubo E, Urakami T, Fatma N, Akagi Y, Singh DP: Polyol pathwaydependent osmotic and oxidative stresses in aldose reductase-mediated apoptosis in human lens epithelial cells: role of AOP2. Biochem Biophys Res Commun 2004, 3 I 4(4): 1050- 056.

26. Váli L, Hahn O, Kupcsulik P, Drahos A, Sárváry E, Szentmihályi K, Pallai Z, Kurucz T, Sípos $P$, Blázovics A: Oxidative stress with altered element content and decreased ATP level of erythrocytes in hepatocellular carcinoma and colorectal liver metastases. Eur J Gastroenterol Hepatol 2008, 20(5):393-398.

27. Tanaka H, Fujita N, Sugimoto R, Urawa N, Horiike S, Kobayashi $Y$, Iwasa M, Ma N, Kawanishi S, Watanabe S, Kaito M, Takei Y: Hepatic oxidative DNA damage is associated with increased risk for hepatocellular carcinoma in chronic hepatitis $\mathrm{C}$. $\mathrm{Br}$ J Cancer 2008, 98(3):580-586.

28. Kuramitsu Y, Nakamura K: Proteomic analysis of cancer tissues: Shedding light on carcinogenesis and possible biomarkers. Proteomics 2006, 6(20):5650-566I.

29. Ezzikouri S, El Feydi AE, Chafik A, Afifi R, El Kihal L, Benazzouz M, Hassar M, Pineau P, Benjelloun S: Genetic polymorphism in the manganese superoxide dismutase gene is associated with an increased risk for hepatocellular carcinoma in HCV-infected Moroccan patients. Mutat Res 2008, 649(I-2): I-6.

30. Kuruma H, Egawa S, Oh-Ishi M, Kodera Y, Satoh M, Chen W, Okusa $\mathrm{H}$, Matsumoto K, Maeda T, Baba S: High molecular mass proteome of androgen-independent prostate cancer. Proteomics 2005, 5(4): |097-IIII2.

3I. Tan S, Seow TK, Liang RC, Koh S, Lee CP, Chung MC, Hooi SC: Proteome analysis of butyrate-treated human colon cancer cells (HT-29). Int J Cancer 2002, 98(4):523-53I.

32. Prasannan P, Pike S, Peng K, Shane B, Appling DR: Human mitochondrial $\mathrm{Cl}$-tetrahydrofolate synthase: gene structure, tissue distribution of the mRNA, and immunolocalization in Chinese hamster ovary calls. J Biol Chem 2003, 278(44):43।78-43|87.

33. Howard KM, Muga SJ, Zhang L, Thigpen AE, Appling DR: Characterization of the rat cytoplasmic $\mathrm{Cl}$-tetrahydrofolate synthase gene and analysis of its expression in liver regeneration and fetal development. Gene 2003, 319:85-97.
Publish with Biomed Central and every scientist can read your work free of charge

"BioMed Central will be the most significant development for disseminating the results of biomedical research in our lifetime. "

Sir Paul Nurse, Cancer Research UK

Your research papers will be:

- available free of charge to the entire biomedical community

- peer reviewed and published immediately upon acceptance

- cited in PubMed and archived on PubMed Central

- yours - you keep the copyright 